\title{
Aplicabiliddate da Teoria dos Poderes Implícitos Na ATIVIdAde de Polícia Judiciária ${ }^{1}$
}

\author{
João Conrado Ponte de Almeida \\ Departamento de Polícia Federal - Brasil

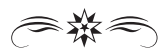

RESUMO

O presente trabalho é uma análise sobre a possibilidade de aplicação, na atividade de polícia judiciária, da Teoria dos Poderes Implícitos, que surgiu através da decisão proferida pela Suprema Corte americana, no caso McCulloch v Maryland, onde ficou definido que deve existir uma relação razoável entre as funções estabelecidas aos órgãos pela Constituição e os meios utilizados por estes para cumprir seu mister e que os meios adotados não podem ser proibidos pela constituição. Tal teoria será contraposta aos princípios da legalidade e da eficiência previstos no artigo 37 da Constituição da República Federativa do Brasil de 1988 com vistas a aplicá-la de forma a atender o princípio da razoabilidade, e não ferir os princípios da segurança jurídica e do devido processo penal.

Palavras-Chave: Teoria dos Poderes Implícitos. Polícia Judiciária. Princípios da legalidade e da eficiência.

\section{INTRODUÇÃ̃o}

A Constituição da República Federativa do Brasil (1988), apesar de prever as atribuições dos órgãos policiais no artigo 144, não apresenta os limites do exercício do poder-dever imposto aos órgãos da segurança pública, prevendo apenas, em seu $\$ 7^{\circ}$, que "lei disciplinará a organização e o funcionamento dos órgãos responsáveis pela segurança pública, de maneira a garantir a eficiência de suas atividades”. (BRASIL, 2012).

1 Artigo científico apresentado à Academia Nacional de Polícia como exigência parcial para a conclusão do Curso de Especialização em Gestão da Investigação Criminal, aprovado pela banca examinadora, a qual fora presidida pelo Dr. Guilherme Cunha Werner e composta pelo Me. Célio Jacinto dos Santos e pelo Me. Rodrigo Carneiro Gomes. 
A doutrina tradicional divide a atividade policial em duas esferas: polícia preventiva e polícia repressiva. A primeira tem como finalidade a prevenção de crimes e a preservação da ordem pública $\left(\$ 1^{\circ}\right.$, II e III, e $\$ 5^{\circ}$ do artigo $144 \mathrm{da} \mathrm{CF} / 88$ ). Por outro lado, a polícia repressiva, conhecida como polícia judiciária, tem como fim a apuração de crimes e a execução de medidas judiciais ( $\$ 1^{\circ}$, I, II e IV do artigo $\left.144 \mathrm{da} \mathrm{CF} / 88\right)$.

A Carta Magna prevê a necessidade de obediência à legalidade e aos direitos individuais, e especialmente ao devido processo legal, sempre que haja a pretensão de atingir direito de outrem (artigo 5 $5^{\circ}$ LIV), bem como exige que o poder público seja eficiente (artigo 37).

De acordo com o princípio da supremacia constitucional, as normas infraconstitucionais e os atos da administração pública devem atender aos ditames da Lei Fundamental, tendo sido recepcionadas e editadas diversas lei que influenciam na atividade policial.

Entretanto, existem lacunas legislativas e interpretações da legislação que dificultam, ou mesmo impossibilitam, a atuação imediata da polícia judiciária, prejudicando a eficiência de suas atividades, como é o caso da condução coercitiva do suspeito para prestar esclarecimentos.

Usando do poder regulamentar do Poder Executivo, previsto no artigo 84, VI, "a" da Constituição e no artigo 6º IV do Decreto-Lei n 200 , de 25 de fevereiro de 1967, os órgãos de polícia judiciária, expedem normas procedimentais internas que norteiam as autoridades policiais, titular das atribuições do órgão, e seus agentes. Contudo, o direito administrativo tem como um de seus princípios a legalidade, que, de acordo com a doutrina e jurisprudência majoritária, valendo-se do princípio da segurança jurídica, impõe à Administração, e por consequência ao servidor, que aja conforme a lei.

Assim, iremos enfrentar os seguintes problemas: a teoria dos poderes implícitos é aplicável à investigação criminal na ordem constitucional brasileira atual? Se sim, então quais os limites?

Para responder esses problemas, será realizada pesquisa na legislação, aplicando-se técnicas hermenêuticas para buscar o espírito do ordenamento jurídico, orientando-se pelos conhecimentos da doutrina, administrativista e constitucional, e da jurisprudência dos tribunais superiores. 


\section{Marco Teórico}

Para que possamos adentrar no mérito da questão proposta, inicialmente devemos definir ideias e conceitos relacionados ao caso.

A Constituição organiza o sistema jurídico e legitima o poder estatal. Ela é o resultado da união entre a política e o direito.

O Brasil, com a Constituição Federal de 1988, tornou-se um Estado Democrático de Direito, onde todo o poder emana do povo (artigo $1^{\circ}$, parágrafo único) e que tem como um de seus princípios a separação e independência dos poderes (artigo $2^{\circ}$ ), e como objetivos fundamentais a promoção do bem de todos (artigo $3^{\circ}$, IV).

O princípio da supremacia da constituição é o alicerce do próprio sistema constitucional brasileiro e consequentemente do Estado. Ele está incutido, implicitamente, no preâmbulo da Constituição e em seu artigo 60 , além de ser pressuposto lógico da validade e legitimidade de todo o ordenamento jurídico.

Partindo dessa conjetura, antes de tratarmos do tema propriamente dito, devemos definir os principais conceitos abordados neste estudo. Primeiramente, por ter relação intrínseca com os atos praticados, devemos definir qual a natureza jurídica da atividade de polícia judiciária. Definida a natureza jurídica, passaremos a analisar o princípio da legalidade, uma vez que este se apresenta como limitador dos poderes estatais. Por fim, definiremos o alcance do princípio da eficiência, por ser o principal fundamento da aplicabilidade da Teoria dos Poderes Implícitos, bem como definiremos tal teoria.

\section{I. NATUREZA JURÍdiCA DA ATIVIDADE DE POLÍCIA JUDICIÁRIA}

Para que possamos analisar a aplicabilidade de qualquer instituto a uma determinada atividade, primeiro devemos definir a natureza jurídica dessa atividade, para que se possa depois avaliar a compatibilidade do instituto com a atividade. Para definirmos a natureza jurídica da atividade de polícia judiciária, devemos, inicialmente, fazer uma análise de toda a atividade estatal. 
Como acontece em qualquer organização, podemos dividir a atividade da administração pública em duas, a atividade-meio e a atividade-fim. Em qualquer órgão ou instituição pública, a máquina administrativa trabalha em duas frentes: uma cumprindo a finalidade constitucional ou legal do órgão/instituição, através da prestação de um serviço público (atividade-fim); e outra que dá o suporte para que essa funcione, disponibilizando e mantendo os recursos necessários para que se cumpra a atividade-fim (atividade-meio).

Diante do princípio da separação e independência dos poderes, previsto no artigo $2^{\circ} \mathrm{da}$ Constituição, pode-se definir a natureza da atividade-fim de acordo os Poderes da União, ou seja, Legislativo, Executivo e Judiciário.

Fazendo uma interpretação legal ou autêntica do sistema jurídico brasileiro, considerando que o único dispositivo legal que trata sobre serviços públicos e poder de polícia é o Código Tributário Nacional, tomando como base seu artigo 77, podemos diferenciar a natureza da atividade-fim do Poder Executivo, ao contrário dos demais poderes, em duas categorias: prestação de serviços públicos em sentido estrito e exercício do poder de polícia. A principal diferença entre essas é que no serviço público em sentido estrito só há, em regra, benefícios para a população atingida (p. ex. estradas, saneamento, educação, saúde etc.), já no poder de polícia existe a incidência de normas infralegais e atos administrativos restritivos de direitos ou de imposição de deveres aos cidadãos (p. ex. conservação do meio ambiente, regulação do trânsito etc.).

Usando da mesma forma de interpretação, através do conceito previsto nesse mesmo artigo, os serviços públicos, no sentido estrito, podem ser divididos em: específicos e divisíveis, como é o caso do transporte público; ou genéricos e indivisíveis, como é o caso da limpeza pública e das obras estatais.

Nessa linha, o artigo 78 do Código Tributário Nacional prevê:

Considera-se poder de polícia atividade da administração pública que, limitando ou disciplinando direito, interesse ou liberdade, regula a prática de ato ou abstenção de fato, em razão de interesse público concernente à segurança, à higiene, à ordem, aos costumes, à disciplina da produção e do mercado, ao exercício de atividades econômicas dependentes de concessão ou autorização do Poder Público, à tranqüilidade pública ou ao respeito à propriedade e aos direitos individuais ou coletivos. (BRASIL, Lei n'. 5.172, de 25 de outubro de 1966, 2012) 
Destarte, no Poder Executivo, a atividade administrativa pode estar relacionada à atividade-meio ou à atividade-fim, e essa última pode se referir a uma prestação de serviço público em sentido estrito ou a um exercício do poder de polícia.

Diogenes Gasparini ensina que o serviço público:

(...) é toda atividade de oferecimento de utilidade ou comodidade fruivel preponderantemente pelos administrados, prestada pela Administração Pública ou por quem lhe faça as vezes, sob um regime de Direito Público, instituido em favor dos interesses definidos como próprios pelo ordenamento jurídico. (GASPARINI, 2006, p. 290).

Para Hely Lopes Meirelles, poder de polícia é:

(...) mecanismo de frenagem de que dispõe a Administração Pública para conter os abusos do direito individual. Por esse mecanismo, que faz parte de toda a Administração. O Estado detém a atividade dos particulares que se revelar contrária, nociva ou inconveniente ao bem-estar social, ao desenvolvimento e à segurança nacional. (MEIRELLES, 2006, p. 122).

Da simples leitura da definição legal de poder de polícia, e considerando as espécies de atividade policial, vemos que somente a polícia preventiva, prevista na primeira parte do $₫ 5^{\circ}$ do artigo 144 da Constituição, poderia se enquadrar no poder de polícia concernente à segurança, à ordem, à tranquilidade pública ou ao respeito à propriedade e aos direitos individuais ou coletivos. Já a atividade de polícia judiciária lato sensu, que engloba a atividade de polícia repressiva (apuração de infrações penais) e a de polícia judiciária stricto sensu (execução de medidas judiciais), não estariam abrangidas no conceito legal de poder de polícia.

Por outro lado, a atividade de polícia judiciária não seria de prestação de serviços público em sentido estrito, já que não existe uma utilidade ou comodidade fruível pelos administrados.

Assim, para buscarmos a natureza da atividade de polícia judiciária no Brasil é imprescindível uma análise histórica e uma digressão do serviço de segurança pública, além de avaliar a participação da atividade de polícia judiciária para a segurança pública. 
É sabido que o serviço de segurança pública é condição sine qua non para a criação e manutenção de um Estado atualmente, já que sem segurança pública não há sequer a organização de um povo, o que faz dele um dos serviços estatais mais essenciais.

Antes das cidades-estados gregas, não havia a organização de um aparato coletivo que prestasse serviço de segurança pública, imperando a lei do mais forte.

Segundo Monet,

(...) na Grécia antiga, na época em que, no resto do mundo, os individuos só podem contar consigo mesmo para preservar sua segurança, que aparecem, pela primeira vez na Europa, e talvez na história da humanidade, agentes especializados, encarregados de fazer respeitar as lei da cidade utilizando a coação física e a ameça de açôes penais. (MONET, 2001, p. 32).

Mas é somente no Império Romano, que:

(...) aparece uma verdadeira administração policial pública, profissional e especializada. Augusto retira do Senado suas responsabilidades tradicinais em relação a Roma e cria o posto de "prefeito da cidade": ao praefectus urbi, doravante, cabe manter a ordem na rua, tomar as disposiçôes necessárias, intentar açôes penais contra os contraventores. (MONET, 2001, p. 34).

David H. Bayley (2001, p. 41) ensina que o cargo de praefectus urbi era preenchido por indicação dos postos mais altos do Senado e tinha a "responsabilidade de manter a ordem pública executiva e judicialmente".

De acordo com Monet (2001, p. 35), "com a queda de Roma, os órgãos especializados de polícia desaparecem da Europa por vários anos".

Na visão de Bayley:

(...) é um erro achar que a polícia pública havia morrido na Europa durante o interregno entre a queda de Roma e a ascensão das Nações-Estados modernas. O policiamento havia se tornado extremamente descentralizado, mas o mesmo havia acontecido com a soberania politica e a autoridade para criar as leis. (BAYLEY, 2001, p. 41). 
Assim, o serviço de policiamento, embora possa ter passado por período de descentralização, existe desde a Grécia antiga.

Já na idade Média, "a divisão da autoridade política é acompanhada de um desmembramento das funções de justiça e segurança" (MONET, 2001, p. 35).

No Brasil, até a chegada da Corte portuguesa, em 1808, as funções de apuração e julgamento de crimes eram concentradas na figura do magistrado, não existindo, efetivamente, um corpo policial com funções específicas de investigação criminal.

Após a independência, com a regulamentação do artigo 162 da Constituição de 1824, foi atribuído ao juiz de paz a função policial e judiciária, sendo o mesmo eleito.

Depois de alguns anos, D Pedro II, através da Lei n 261, de 03 de dezembro de 1841, atribuiu a função de Chefe de Polícia a Desembargadores e Juízes de Direito, mantendo unidas as funções de apurar e julgar os crimes.

Nos ensinamentos de José Pedro Zaccariotto:

À polícia judiciária de então, quase sempre exercida por magistrados togados, competia mais que a apuração das infrações penais (função criminal), cabendo-lhe também o processo e o julgamento dos chamados "crimes de polícia" (função correcional). (ZACCARIOTTO, 2005, p. 60).

Somente com a edição da Lei $\mathrm{n}^{\circ} .2 .033$, de 20 de setembro de 1871, e do Decreto ${ }^{\circ}$. 4.824, de 22 de novembro de 1871, separou-se as funções jurisdicionais e investigativa, retirando-se das autoridades policiais o julgamento de quaisquer ilícitos penais, e instituindo o inquérito policial como o principal meio de apuração de infrações penais. Esse sistema está mantido até a atualidade.

Conforme a Exposição de Motivos do Código de Processo Penal, o inquérito policial, qualificado como instrução provisória, foi mantido como processo preliminar da ação penal. Segundo tal exposição, a criação do juízo de instrução, em que haveria a limitação da função da autoridade policial a efetuar a prisão e a averiguar a materialidade do crime e indicar testemunhas, não seria possível diante das peculiaridades do país. O inquérito, segundo tal documento, é: 
Aplicabilidade da Teoria dos Poderes Implícitos na Atividade de Polícia Judiciária

(...) uma garantia contra apressados e errôneos juizos, formados quando ainda persiste a trepidação moral causada pelo crime ou antes que seja possivel uma exata visão de conjunto dos fatos, nas suas circunstâncias objetivas e subjetivas. Por mais perspicaz e circunspeta, a autoridade que dirige a investigação inicial, quando ainda perdura o alarma provocado pelo crime, está sujeita a equivocos ou falsos juizos a priori, ou a sugestôes tendenciosas. (...) nosso sistema tradicional, com o inquérito preparatório, assegura uma justiça menos aleatória, mais prudente e serena. (BRASIL, Exposição de Motivo do Código de Processo Penal, 1941).

Com a evolução do Estado, e a consequente divisão das atribuições, ficou evidenciada a necessidade de separação do serviço de segurança, ou seja, a polícia preventiva, do serviço judiciário. Com isso, dividiu-se a polícia em duas: uma que atua para preservar a ordem pública e evitar a prática de crimes (polícia preventiva), e outra que atua na apuração de crimes e na execução de medidas judiciais (polícia repressiva).

A polícia judiciária, como polícia repressiva, tem como principal finalidade dar suporte ao sistema judiciário, seja assumindo o papel de Estado-Investigador, na persecução penal, seja fazendo cumprir as ordens judiciais. Por outro lado, seu serviço tem influência na segurança pública, por desincentivar e até inibir a prática de crimes.

Assim, o serviço de polícia judiciária teria repercussão tanto na gestão da justiça como na gestão da segurança pública.

Nessa linha, Luigi Ferrajoli, ensina:

A policia, escreveu Walter Benjamin, é uma 'mescla' de 'duas espécies de violência: aquela que 'póe e que conserva o direito', em via de principio separada e destinada respectivamente ao Poder Legislativo e aquele Judiciário, além de obviamente, ao Poder Executivo. Esta sua particular caracteristica, que a torna participante de todos os poderes do Estado, depende da ambigüidade do seu papel e da sua colocação institucional. A polícia é, de fato, uma atividade administrativa formalmente organizada e dependente do Poder Executivo. Diversamente de outros ramos da administração pública, ela é uma administração que tem diretamente que ver com as liberdades fundamentais; e tem que ver não apenas enquanto função auxiliar da jurisdição, mas também, em virtude de competências próprias e autônomas, como aquelas variantes preventivas e cautelares, exercidas em relação aos sujeitos perigosos ou suspeitos. (2002, p. 615 e 616). 
Para Ferrajoli, a Polícia Judiciária tem uma configuração ambígua, tendo função administrativa, auxiliar à judiciária. Citando Walter Benjamin, o mesmo autor (FERRAJOLI, 2002, p. 616) defende que a Polícia Judiciária está em uma zona limite entre legislação e jurisdição, "gozando da discricionariedade de uma e da força da outra”.

Por todo o exposto, podemos concluir que, apesar de o órgão estar ligado ao Poder Executivo, seja em razão de lei (caso da Polícia Federal), seja em razão da própria Constituição, as polícias judiciárias, assim como o Ministério Público, desenvolvem atividade de natureza sui generis, não se enquadrando em nenhum dos Poderes, já que realiza atividade executiva, com implicações na política de segurança pública, mas de interesse da atividade jurisdicional do Estado.

\subsection{PRINCÍPIO DA LEGALIDADE DA ADMINISTRAÇÃo PÚBLICA}

Outro conceito importante para este trabalho é o da legalidade na medida em que além de ser um dos princípios da administração pública, previsto no artigo 37 da Constituição, apresenta-se como principal limitação do poder estatal, podendo ser o principal óbice à aplicação da Teoria dos Poderes Implícitos.

A Constituição de 1988 adotou o sistema rígido, no qual limita o poder constituinte derivado, dificultando ou impedindo alteraçóes, o que a torna superior às demais normas positivas.

Através da análise de tais limitações, podemos verificar, no $₫ 4^{\circ}$ do artigo 60, que o legislador constituinte elegeu algumas normas como imutáveis, as chamadas cláusulas pétreas, que são: forma federativa de Estado; o voto direto, secreto, universal e periódico; a separação dos Poderes, e; os direitos e garantias individuais.

Assim, os direitos e garantias individuais possuem uma especial proteção constitucional. Essa imutabilidade indica, de certa forma, a importância dada pela Constituição, demonstrando que o legislador constituinte entendeu que tais dispositivos eram mais relevantes que as demais normas constitucionais. Daí surge a ideia de que os direitos e garantias individuais devem se sobrepor aos interesses do Estado, até porque esse foi criado para servir seu povo. 
Entretanto, havendo uma contraposição de direitos individuais de várias pessoas em relação aos de uma única pessoa, qual deveria prevalecer? Parte da doutrina defende que seria dessa última, posto que o Estado existiria justamente para proteger o cidadão. Contudo, se assim o fosse, como explicar a legitimidade da imposição de uma pena pelo Estado? A solução estaria no poder que o Estado detém de editar normas, ou seja, de criar regras juridicamente válidas que, uma vez infringidas, resulta na possibilidade de restrições aos direitos individuais do responsável. Assim não existiria direito absoluto.

Por outro lado, para que esses direitos sejam garantidos pelo Estado, a Carta Magna previu a existência de entes, poderes, instituições e órgãos, que detêm uma parcela do poder estatal para servir à nação. Para cada um desses, a Constituição prevê um poder-dever. Ora, se a Constituição impõe a alguém um dever, esse não poderia alegar, salvo nos casos expressamente previstos na Lei Maior, falta de lei regulamentadora para se eximir de suas obrigações, pois assim se aceitaria a limitação da eficácia da própria Constituição, quando esta não o faz.

Mas quais seriam os limites do exercício desse poder-dever? A resposta se encontra nas demais normas constitucionais, como é o caso do artigo 37, a qual prevê que a administração pública obedecerá, dentre outros, ao princípio de legalidade, impessoalidade, moralidade, publicidade e eficiência.

Acontece que tais princípios não foram conceituados ou definidos constitucionalmente, onde se inclui a legalidade.

O princípio da legalidade, em sua versão tradicional, indica que somente a lei, como expressão da vontade do povo, pode inovar de forma original no ordenamento jurídico.

Tal princípio está previsto em vários outros dispositivos constitucionais. É um princípio do Direito Penal, no qual assegura que "não há crime sem lei anterior que o defina, nem pena sem prévia cominação legal" (artigo $5^{\circ}$, inciso XXXIX), bem como é um princípio de limitação ao poder de tributar (artigo 150, inciso I).

Para José Afonso da Silva, o princípio da legalidade não se confunde com o princípio da reserva legal. Segundo Silva (2000, p. 421), "o primeiro significa a submissão e o respeito à lei, ou a atuação dentro da esfera estabelecida pelo legislador. O segundo consiste em estatuir que a regulamentação de 
determinadas matérias há de fazer-se necessariamente por lei". O princípio da legalidade teria uma abrangência mais ampla e exigiria apenas norma válida emanada de órgão competente. Já a reserva legal, segundo o mesmo autor, exigiria norma válida emanada do Poder Legislativo e só se aplicaria nos casos expressamente previstos na Constituição. Assim, o princípio da reserva legal seria derivado do princípio da legalidade.

Silva (2000, p. 421) divide o princípio da reserva legal em duas espécies: absoluta, na qual a lei deve esgotar toda a regulamentação do caso; e relativa, na qual a lei estabeleceria condições e limites a serem seguidos pelas normas infralegais.

Como vimos a legalidade está presente em vários ramos do Direito, podendo essa ser de ordem pública ou de ordem privada. Na esfera privada, o princípio da legalidade assegura que os particulares podem fazer tudo que a lei não proíba, já para a administração pública, o princípio da legalidade impõe que a Administração só pode fazer o que a lei determine ou autorize.

Em relação ao que a lei determina, não há dúvida. Contudo, quando se trata daquilo que a lei autoriza, surgem grandes divergências doutrinárias e jurisprudenciais.

Assim, o termo "legalidade" pode ser usado em pelo menos três acepções: em seu sentido estrito ou tradicional, como sinônimo de reserva legal, em que somente a lei, emanada do poder legislativo, pode regular o caso; no sentido amplo, como sinônimo de legislação, na qual qualquer norma juridicamente válida pode regular o fato, desde que não contrária à lei, e; como sinônimo de licitude, em que se pode adotar qualquer ato que não seja proibido pela legislação.

O princípio da legalidade penal e tributária não pode se confundir com o princípio da legalidade da administração pública, já que nos dois primeiros casos estão intrinsecamente ligados a uma obrigação ou restrição de direitos dos cidadãos, já no último pode estar relacionado à prestação de serviço à população.

Em matéria penal e tributária, a jurisprudência do STF aplica o princípio da legalidade no sentido de reserva legal, conforme os exemplos que seguem: 
Aplicabilidade da Teoria dos Poderes Implícitos na Atividade de Polícia Judiciária

DIREITO CONSTITUCIONAL E TRIBUTÁRIO. RECURSO EXTRAORDINÁRIO. CONVÊNIO ICMS 91/91. ISENÇÃO DE ICMS. REGIME ADUANEIRO ESPECIAL DE LOJA FRANCA. "FREE SHOPS” NOS AEROPORTOS. PROMULGACATO DE DECRETO LEGISLATIVO. ATENDIMENTO AO PRINCÍPIO DA LEGALIDADE ESTRITA EM MATÉRIA TRIBUTÁRIA. 1. Legitimidade, na hipótese, da concessão de isenção de ICMS, cuja autorização foi prevista em convênio, uma vez presentes os elementos legais determinantes para vigência e eficácia do benefício fiscal. 2. Recurso extraordinário conbecido, mas desprovido. (BRASIL, Supremo Tribunal Federal, RE 539130 RS, Relator: Min. Ellen Gracie, 2009)

Ementa: PENAL E PROCESSUAL PENAL. RECURSO ORDINÁRIO EM HABEAS CORPUS. ESTELIONATO NA MODALIDADE "DISPOSIÇÃO DE COISA ALHEIA COMO PRÓPRIA" (CP, ART. 171, \& 20, INC. I). PRETENSA ATIPICIDADE, PORQUANTO A NORMA PENAL INCRIMINA A PROMESSA FRAUDULENTA DE COMPRA E VENDA DE IMÓVEL, E NÃO A VENDA. VIOLAÇÃO DO PRINCÍPIO DA LEGALIDADE ESTRITA. IMPROCEDÊNCIA DOS ARGUMENTOS ARTICULADOS NA INICIAL, UMA VEZ QUE HA PROVA ROBUSTA APONTANDO PARA A VENDA FRAUDULENTA. IMPOSSIBILIDADE DO REEXAME DE FATOS E PROVAS, EM HABEAS CORPUS, DA AÇÃO PENAL VIA WRIT. EXCEPCIONALIDADE. RECURSO NATO PROVIDO. 1. O artigo 171 do Código Penal tipifica, in genere, o crime de estelionato, ao passo que seu $\$ 2^{\circ}$ e inciso I dispóem, respectivamente, que "nas mesmas penas incorre quem" "vende, permuta, dá em pagamento, em locação ou em garantia coisa albeia como própria". Trata-se do estelionato caracterizado pela disposição de coisa alheia como própria. O inciso I do $\$ 2^{\circ}$ do art. 171 prevê cinco condutas típicas: venda, permuta, dação em pagamento, em locação ou em garantia. 2. O verbo vender expressa, exclusivamente, a compra e venda, não incluindo o mero compromisso de compra e venda. Doutrina. 3. As razóes da impetração visam a demonstrar que o paciente não praticou nenhuma das condutas tipificadas no referido inciso Ido $\$ 2^{\circ}$ do art. 171 do CP, uma vez que apenas firmou contratos de promessa de compra e venda de imóveis, e não a venda propriamente dita. Por isso que a imputação do crime que lhe éfeita violaria o princípio da legalidade estrita, que deve ser observado em se tratando de norma penal incriminadora. 4. De fato, em se tratando de normas penais incriminadoras, não há falar em analogia ou qualquer outro método de integração com o escopo de incriminar. 5. In casu, os elementos probatórios coligidos nos autos 
indicam que o recorrente vendeu a outrem, como se fosse seu, um lote residencial, sendo condenado a 1 (um) ano e 4 (quatro) meses de reclusão pelo crime de estelionato. 6 . A adoção de entendimento diverso demandaria aprofundado reexame de fatos e provas, insuscetivel em sede de habeas corpus. 7. O trancamento de ação penal por intermédio do habeas corpus é medida excepcionalissima, justificando-se somente quando despontar fora de dúvida a ausência de materialidade ou de autoria ou alguma excludente de tipicidade ou de punibilidade, o que não é o caso destes autos. Precedentes: HHCC 99.740, Rel. o Min. Carlos Britto, $2^{a}$ Turma, DJe de 1/2/2011; 100.246, Rel. Min. Joaquim Barbosa, 2a Turma, DJe de 29/4/2011; 101. 012, Rel. Min. Ricardo Lewandowski, $1^{a}$ Turma, DJe de 10/12/201 e 106.271, Rel. Min. Cármen Lúcia, $1^{a}$ Turma, DJe de 6/5/2011. 8. Recurso ordinário em habeas corpus ao qual se nega provimento. (BRASIL, Supremo Tribunal Federal, RHC 95782 MG, Relator: Min. Luiz Fux, 2011).

No âmbito da administração pública, Hely Lopes Meirelles (2006, p. 42), ensina, de forma clássica, que "enquanto na administração particular é lícito fazer tudo que a lei não proíbe, na Administração Pública só é permitido fazer o que a lei autoriza”.

Na mesma linha, Celso Antônio Bandeira de Mello defende que somente a lei pode inovar, criando ou restringindo direitos, e Diógenes Gasparini defende que o particular pode fazer tudo o que a lei permite e tudo o que a lei não proíbe, já a Administração só pode agir quando e da forma que a lei autoriza, não podendo atuar quando não houver lei sobre o caso.

No entanto, o termo lei, pode ter, pelo menos dois sentidos: sentido estrito, ou seja, ato normativo geral expedido pelo Poder Legislativo; e sentido amplo, como sinônimo de legislação, abrangendo normas expedidas por todos os poderes.

Dessa forma, a legalidade se aplicaria sob dois aspectos: quanto a fonte da norma regulamentadora, se lei ou norma infralegal, e na existência de prévia regulamentação, seja por lei, seja por norma infralegal.

Assim, se o caso envolvesse fato abrangido pela reserva legal, somente poderia se aplicar a lei em sentido restrito. Já se o caso não fosse abrangido pela reserva legal, poder-se-ia aplicar qualquer tipo de norma. Contudo, em ambos os casos, haveria a exigência de prévia regulamentação através de norma positivada. 
Aplicabilidade da Teoria dos Poderes Implícitos na Atividade de Polícia Judiciária

Essa noção do princípio da legalidade vem sofrendo uma transformação fundamental na passagem para o Estado Social, com o surgimento de novas funções do Estado, por demanda da população.

Seguindo essa tendência, foi promulgada a Emenda Constitucional $\mathrm{n}^{\circ} .19$, de 04 de junho de 1998 , incluindo a eficiência como um dos princípios da administração pública, surgindo a necessidade de harmonização desses dois princípios, ou seja, a imposição da legalidade não pode mais impedir ou inviabilizar a ação estatal, devendo ser aplicado o princípio da proporcionalidade, em que os meios devem ser proporcionais aos fins, de forma a compatibilizar tais princípios.

\section{Para Vladimir França:}

Os princípios jurídicos não devem ser encarados como compartimentos estanques, incomunicáveis, épreciso que o operador jurídico compreenda que os principios da legalidade, da impessoalidade, da moralidade, da publicidade e da eficiência são elementos que devem ser conjugados para o melhor entendimento do regime jurídico-administrativo. (FRANÇA, 2001).

Como vimos acima, em razão da existência de atividades de naturezas distintas, surge a seguinte pergunta: os princípios constitucionais devem ser aplicados da mesma forma em todas as atividades estatais? A legalidade exigida para a execução do serviço público no sentido estrito é a mesma para executar um poder de polícia?

Para responder essa pergunta, raciocinemos: para que seja prestado um novo serviço público seria razoável a necessidade de lei em sentido estrito? E para ser criada uma nova atividade que envolva poder de polícia, é plausível a exigência de lei em sentido estrito? Na primeira, por abranger somente benefício para a população, a resposta mais prudente seria não. Já na segunda, por envolver restrições a direitos dos cidadãos, a resposta indicada seria sim.

Desse modo, com base no princípio da razoabilidade, existem atos que o Estado só pode executar se for autorizado expressamente por lei em sentido estrito, como é o caso da cobrança de impostos. Por outro lado, existem situações em que a administração pública pode atuar mesmo sem a existência de lei formal que regule o ato, como foi o caso da criação da Força Nacional de Segurança Pública. 
Assim, podemos concluir que a acepção do termo "legalidade" é flexível, podendo ser graduado, de modo a atender ao princípio da proporcionalidade, devendo se harmonizar com a natureza jurídica do bem envolvido e com as circunstâncias do caso. Quanto mais precioso o bem jurídico, maior deve ser o rigor da "legalidade", havendo casos que a própria Constituição reserva a regulação à lei complementar.

Nesse sentido, aplica-se, ainda, o princípio da finalidade, através do qual, para que os efeitos da norma sejam legítimos, deve ser mantido o espírito da lei. Tal princípio não é uma mera:

(...) decorrência do princípio da legalidade. É mais do que isso: é uma inerência dele; está nele contido, pois corresponde à aplicaçãa da lei tal qual é; ou seja, na conformidade de sua razão de ser, do objetivo em vista do qual foi editada. Por isso se pode dizer que tomar uma lei como suporte para a prática de ato desconforme com sua finalidade não é aplicar a lei; é desvirtuá-la; é burlar a lei sob pretexto de cumpri-la. (MELLO, 2009, p. 106).

Dessa forma, o conceito do princípio da legalidade da administração pública vem, com o advento do pensamento pós-positivista e da introdução do princípio da eficiência, aproximando-se da ideia da juridicidade, ou seja, conformidade com o Direito, em que a administração pública, para atuar legitimamente, não pode se restringir à letra da lei, devendo buscar atender aos preceitos e espírito do sistema normativo, onde se incluem os princípios, os valores e os fundamentos.

Assim, no Estado social, o princípio da legalidade passa a ser mais abrangente, incluindo a noção do:

(...) princípio da juridicidade da administração, entendido como a subordinação ao direito como um todo, implicando submissão a princípios gerais de direito, à Constituição, a normas internacionais, a disposiçôes de caráter regulamentar, a atos constitutivos de direitos, etc. (ESTORNINHO, 1999).

Maria João Estorninho conclui que:

(...) o princípio da legalidade deixa assim de ter uma formulação unicamente negativa (como no periodo do Estado Liberal), para passar a ter uma formulação positiva, constituindo o fundamento, o critério e o limite de toda atuação administrativa. (ESTORNINHO, 1999). 
Aplicabilidade da Teoria dos Poderes Implícitos na Atividade de Polícia Judiciária

Vladimir da Rocha França (2000, p. 168) afirma que "toda ação administrava deve ser orientada para concretização material e efetiva da finalidade posta pela lei, segundo os cânones jurídico-administrativo".

É corolário dessa ideia a Emenda Constitucional no. 32 de 2001, quando alterou a redação do inciso VI do artigo 84 da Carta Magna, para possibilitar ao Presidente da República dispor mediante decreto sobre a organização e o funcionamento da administração federal. Outro corolário é o inciso I do parágrafo único do artigo $2^{\circ}$ da Lei $n^{\circ}$. 9.784, de 29 de janeiro de 1999 , ao prever a atuação conforme a lei e o Direito no processo administrativo.

Esse entendimento já pode ser constatado na jurisprudência, conforme exemplos a seguir:

CONSTITUCIONAL. ADMINISTRATIVO. AQUISIÇÃO DE IMÓVEL PRÓPRIO FUNCIONAL ADMINISTRADO PELO HOSPITAL DAS FORCAS ARMADAS. NORMA OPERACIONAL No O07/GAB/DIR/HFA. PREVALENNCIA DE CRITÉRIOS EMINENTENTE FUNCIONAIS EM DETRIMENTO DE CRITÉRIOS SÓCIO-ECONÔMICOS QUE SE AFASTA. TEOLOGIA DA NORMA QUESTIONADA. PRINCÍPIO DA RAZOABILIDADE E DA JURIDICIDADE, QUE ULTRAPASSA AO DA LEGALIDADE ESTRITA. ESTADO DE DIREITO. SENTENCCA MANTIDA. APELAÇÃO E REEXAME NECESÁRIO NÃO PROVIDOS. 1. A aquisição de imóvel próprio funcional administrado pelo Hospital das Forças Armadas, na forma em que veiculada na Norma Operacional no 007/GAB/DIR/HFA, privilegia critério eminentemente funcional, em detrimento de critérios sócio-econômicos, distanciando-se, assim, de seu objetivo perseguido. Norma que se afasta na espécie. 2. O critério perseguido pela aludida norma está muito mais ligado ao princípio constitucional da moradia - necessidade de habitação, concessão de imóvel funcional para residência - do que à concessão de benesse puramente funcional. 3. Demonstrado nos autos o grau de fragilidade social e econômica do impetrante, não é razoável a prevalência dada pela norma objurgada ao critério eminentemente funcional, conclusão que, nem de longe, tem o condão de invadir o mérito administrativo, eque apenas colmata o regramento administrativo aos fins sociais a que a norma se dirige e às exigências do bem comum. 4. Não é conferido ao Público Administrador afastar-se do princípio da razoabilidade, projeção que, atinente ao princípio da juridicidade, que lhe é superior, encampa o da 
mera legalidade estrita, mormente em um Estado que se intitula como sendo de Direito. 5. Apelação e reexame necessário não providos. Sentença mantida. (BRASIL, Tribual Regional Federal 1 Região, AC. 200434000122295 DF, Relator: Juiz Federal Marcelo Dolzany da Costa, 2013) (grifo nosso).

Através de tal exemplo, vemos que até Poder Judiciário vem flexibilizando a definição da legalidade de acordo com a situação concreta, harmonizando-a com outros princípios e regras constitucionais que incidem no caso, amoldando a legalidade ao sentido da juridicidade, possibilitando a aplicação da Teoria dos Poderes Implícitos.

\subsection{PRINCÍPIO DA EFICIÊNCIA DA ADMINISTRAÇÃo PÚBLICA}

A constitucionalização do princípio da eficiência pode ser considerada controvérsia a legalidade estrita, na medida em que a legalidade não pode impedir à efetividade da atuação estatal quando houver meios disponíveis. Assim, a omissão legislativa não poderia ser causa da inércia do Estado.

Atuar de forma eficiente é utilizar o meio mais proveitoso para se atingir um determinado fim. É a otimização dos meios disponíveis frente ao objetivo buscado.

Juridicamente, eficiência difere de eficácia. Eficácia implica em atingir a meta, enquanto que a eficiência implica em adotar o melhor meio possível para se obter o resultado. Ser eficaz não implica ser eficiente, uma vez que se pode adotar o meio mais oneroso para se atingir seu termo. Por outro lado, a eficiência implica eficácia, uma vez que a escolha do melhor meio deve resultar no sucesso de seu objetivo.

É sabido que, em regra, existem necessidades ilimitadas em qualquer sociedade, enquanto que os recursos são escassos. Da mesma forma, no Brasil, é sabido que, apesar da enorme carga tributária, os recursos públicos disponíveis, sejam eles humanos, materiais ou financeiros, não vem sendo suficientes para atender a totalidade da demanda imposta à administração pública pela Constituição Federal.

Assim, e diante do princípio da proibição da insuficiência dos meios, através do qual se proíbe a omissão estatal em relação às suas obrigações cons- 
Aplicabilidade da Teoria dos Poderes Implícitos na Atividade de Polícia Judiciária

titucionais, a administração pública tem que atuar de forma eficiente, adequando os meios disponíveis aos fins pretendidos.

Mesmo antes da chamada reforma administrativa, feita através da promulgação da Emenda Constitucional nº. 19, de 04 de junho de 1998, que, entre outras mudanças, introduziu a eficiência como princípio da administração pública, Hely Lopes Meirelles já defendia a eficiência como dever da Administração Pública:

Dever de eficiência é o que se impõe a todo agente público de realizar suas atribuiçôes com presteza, perfeição e rendimento funcional. É o mais moderno principio da função administrativa, que já não se contenta em ser desempenhada apenas com legalidade, exigindo resultados positivos para o serviço público e satisfatório atendimento das necessidades da comunidade e de seus membros. Esse dever de eficiência, bem lembrado por Carvalho Simas, corresponde ao dever de 'boa administração' da doutrina italiana, o que já se acha consagrado, entre nós, pela Reforma Administrativa Federal do Dec.-Lei 200/67, quando submete toda atividade do Executivo ao controle de resultado (arts. 13 e 25,V), fortalece o sistema de mérito (art. 25, VIII), sujeita a Administração indireta a supervisão ministerial quanto à eficiência administrativa (art. 26, III) e recomenda a demissão ou dispensa do servidor comprovadamente ineficiente ou desidioso (art. 100). (MEIRELLES. 1997, p. 90).

O princípio da eficiência tem origem no direito privado. Ele é o resultado das necessidades impostas pela globalização e pelo neoliberalismo e pela política do modelo do Estado mínimo, numa reação à herança burocrática brasileira.

Maria Sylvia Zanella Di Pietro (2002, p. 83) afirma que o princípio da eficiência:

(...) apresenta dois aspectos: pode ser considerado em relação ao modo de atuação de agente público, do qual se espera o melhor desempenho possivel de suas atribuições, para lograr os melhores resultados; e em relação ao modo de organizar, estruturar, disciplinar a Administração Pública, também com o mesmo objetivo de alcançar os melhores resultados na prestação do serviço público. (PIETRO, 2002, p. 83).

Já para Alexandre de Moraes, o princípio da eficiência: 
(...) impõe à Administração Pública direta e indireta e a seus agentes a persecução do bem comum, por meio do exercício de suas competências de forma imparcial, neutra, transparente, participativa, eficaz, sem burocracia e sempre em busca da qualidade, primando pela adoção dos critérios legais e morais necessários para melhor utilização possivel dos recursos públicos, de maneira a evitar-se desperdicios e garantir-se uma maior rentabilidade social. Nota-se que não se trata de consagração da tecnocracia, muito pelo contrário, o princípio da eficiência dirige-se para a razão e fim maior do Estado, a prestação de serviços essenciais à população, visando a adoção de todos os meios legais e morais possiveis para a satisfação do bem comum. (MORAES, 1999, p 30).

Ao contrário das empresas privadas, que convivem com a competitividade e têm na eficiência uma necessidade de sobrevivência, a administração pública, por prestar serviços essenciais para a população, tem na eficiência um dever intangível. Por outro lado, havendo a cobrança, direta ou indireta, pelos serviços públicos, por meio dos tributos, a eficiência se torna um direito dos cidadãos.

Nesse sentido, Hely Lopes Meirelles (1997, p. 89) ensina que "na administração prestadora, constitutiva, não basta ao administrador atuar de forma legal e neutra, é fundamental que atue com eficiência, com rendimento, maximizando recursos e produzindo resultados satisfatórios".

Por ser um princípio constitucional, a eficiência não se aplica apenas na execução de serviços públicos, passando a ser uma meta geral a ser atingida pela Administração, devendo orientar a edição e interpretação das normas que regulam as atividades do Estado.

\subsection{TEORIA DOS PODERES IMPLÍCITOS}

A Teoria dos Poderes Implícitos surgiu na decisão proferida pela Suprema Corte Americana, no caso McCulloch v Maryland, na qual ficou definido que deve existir uma relação razoável entre as funções estabelecidas aos órgãos pela Constituição e os meios utilizados por estes para cumprir sua incumbência e que os meios adotados não podem ser proibidos pela própria constituição.

Essa teoria defende que ao serem definidos os objetivos e as competências dos órgãos, ela, implicitamente, concede aos mesmos a liberdade de 
Aplicabilidade da Teoria dos Poderes Implícitos na Atividade de Polícia Judiciária

adotar os mecanismos necessários para cumprir suas obrigaçóes, sendo-lhe vedada apenas o que a constituição proíbe.

Vemos que a aplicação de tal teoria se coaduna com a mudança de paradigma da legalidade administrativa. Com isso, a lei, em sentido estrito, deixaria de ser o trilho a ser seguido pelo agente público, passando a ser suas balizas.

Desse modo, a Constituição daria à Administração a possibilidade de adotar as medidas necessárias para cumprir suas atribuições, mesmo sem a existência de lei em sentido estrito que prescreva expressamente tal ato. Contudo, a medida não poderia, é claro, ser contrária a lei, ou ao ordenamento jurídico, nem destoar de possível norma legal que regule o caso.

Destarte, a teoria dos poderes implícitos teria a função de integrar o ordenamento jurídico, impedindo que a administração se omita por falta de lei que regule o caso. Para tanto, dever-se-ia seguir o espírito da Lei de Introdução ao Código Civil Brasileiro, classificada como norma supralegal pela doutrina e jurisprudência dominantes, a qual prescreve em seu do artigo $4^{\circ}$ que "quando a lei for omissa, o juiz decidirá o caso de acordo com a analogia, os costumes e os princípios gerais de direito". (BRASIL, Decreto-Lei n. 4.567, de 04 de setembro de 1942, 2012).

Nessa linha, a Teoria dos Poderes Implícitos se adequa também ao princípio da eficiência, já que se torna um mecanismos de legitimação dos atos da Administração mesmo sem a existência de lei regulando expressamente o caso.

O Poder Judiciário vem aplicando a Teoria dos Poderes Implícitos em várias atividades estatais, como é o caso do Tribunal de Contas e do Ministério Público, conforme exemplo a seguir:

HABEAS CORPUS" - CRIME DE TORTURA ATRIBUÍDO
A POLICIAL CIVIL - POSSIBILIDADE DE O MINISTÉ-
RIO PÚBLICO, FUNDADO EM INVESTIGAÇÃO POR
ELE PRÓPRIO PROMOVIDA, FORMULAR DENUNCIA
CONTRA REFERIDO AGENTE POLICIAL - VALIDA-
DE JURIDICA DESSA ATIVIDADE INVESTIGATÓRIA
- CONDENAÇAOO PENAL IMPOSTA AO POLICIAL TOR-
TURADOR - LEGITIMIDADE JURIDICA DO PODER
INVESTIGATÓRIO DO MINISTERIO PÚBLICO - MO-
NOPÓLIO CONSTITUCIONAL DA TITULARIDADE DA 
AÇÃO PENAL PÚBLICA PELO "PARQUET" - TEORIA DOS PODERES IMPLÍCITOS - CASO "McCULLOCH v. MARYLAND" (1819) - MAGISTÉRIO DA DOUTRINA (RUI BARBOSA, JOHN MARSHALL, JOÃO BARBALHO, MARCELLO CAETANO, CASTRO NUNES, OSWALDO TRIGUEIRO, v.g.) - OUTORGA, AO MINISTÉRIO PÚBLICO, PELA PRÓPRIA CONSTITUIÇÃO DA REPÚBLICA, $D O$ PODER DE CONTROLE EXTERNO SOBRE A ATIVIDADE POLICIA $L$ - LIMITACÕES DE ORDEM JURÍDICA AO PODER INVESTIGATÓRIO DO MINISTÉRIO PÚBLICO - "HABEAS CORPUS" INDEFERIDO. NAS HIPÓTESES DE AÇÃO PENAL PÚBLICA, O INQUÉRITO POLICIAL, QUE CONSTITUI UM DOS DIVERSOS INSTRUMENTOS ESTATAIS DE INVESTIGAÇÃO PENAL, TEM POR DESTINATÁRIO PRECÍPUO O MINISTÉRIO PÚBLICO. (...) $\mathrm{O}$ poder de investigar compóe, em sede penal, o complexo de funções institucionais do Ministério Público, que dispõe, na condição de "dominus litis" e, também, como expressão de sua competência para exercer o controle externo da atividade policial, da atribuição de fazer instaurar, ainda que em caráter subsidiário, mas por autoridade própria e sob sua direção, procedimentos de investigação penal destinados a viabilizar a obtenção de dados informativos, de subsídios probatórios e de elementos de convicção que lhe permitam formar a "opinio delicti”, em ordem a propiciar eventual ajuizamento da ação penal de iniciativa pública. (BRASIL, Supremo Tribunal Federal, HC: 89837 DF, Relator: Min. Celso de Mello, 2009) (grifos nosso).

PROCESSUAL CIVIL - VIOLAÇÃO DO ARTIGO 332 DO CPC, DO ARTIGO 50 DA LEI N. 9.784/99 E DOS ARTS. 10, INCISO IX, E 24 DA LEI N. 4.595/64 - PREQUESTIONAMENTO NÄO CONFIGURADO - VIOLAÇÃO DO ART. 453 DO CPC - INEXISTÊNCIA - SÚMULA 83/STJ - VIOLAÇÃO DO TRATADO DE BASILEIA - AUSÊNCIA DE FUNDAMENTAÇÃO - SÚMULA 284/STF - POTENCIALIDADE DE PREJUÍZO - FISCALIZAÇÃO POR TRIBUNAL DE CONTAS DE INSTITUICÃO FINANCEIRA ESTATAL - POSSIBILIDADE - DECISAOO DO TRIBUNAL DE ORIGEM, EM TODOS OS FUNDAMENTOS, DE ACORDO COM A JURISPRUDENNCIA DESTA CORTE - SÚMULA 83/STJ - INTENÇÃO GERAL DE REVOLVIMENTO DE MATÉRIA FÁTICO-PROBATÓRIA - INCIDÊNCIA DA SÚMULA 7/STJ. (...). 5. Todos os sistemas e órgãos de controle e fiscalização de recursos públicos devem, em uma República, 
Aplicabilidade da Teoria dos Poderes Implícitos na Atividade de Polícia Judiciária

ser valorizados e dotados de poderes implícitos idôneos para que sejam atingidos os fins constitucionais. (BRASIL, Superior Tribunal de Justiça, AgRg no REsp: 1119799 DF 2009/00152963, Relator: Ministro Humberto Martins, 2009) (grifo nosso).

\section{Organização e Regulação do Funcionamento da Polícia Judiciária}

Apesar da natureza sui generis das atividades de polícia judiciária, tanto a Polícia Federal, como as Polícias Civis, são órgãos ligados ao Poder Executivo, seja por imperativo constitucional, seja por previsão legal.

O artigo 84 da Carta Magna, com a promulgação da Emenda Constitucional $n^{\circ} .32$, passou a prever:

Compete privativamente ao Presidente da República:

(...)

$V I$ - dispor, mediante decreto, sobre:(Redação dada pela Emenda Constitucional $n^{\circ} 32$, de 2001)

a) organização e funcionamento da administração federal, quando não implicar aumento de despesa nem criação ou extinção de órgãos públicos; (Incluida pela Emenda Constitucional no 32, de 2001)

(BRASIL, Constituição da República Federativa do Brasil, 2012).

Assim, cabe ao Presidente da República dispor, através de decreto, sobre a organização e o funcionamento dos órgãos que compõem a administração federal, onde se incluiria os órgãos de polícia judiciária. Da mesma forma, pelo princípio constitucional da simetria, nos Estados, o Governador teria poder-dever semelhante. Essa seria a regra.

Contudo, como vimos acima, o $\$ 7^{\circ}$ do artigo 144 da Constituição Federal prevê que "a lei disciplinará a organização e o funcionamento dos órgãos responsáveis pela segurança pública, de maneira a garantir a eficiência de suas atividades". (BRASIL, Constituição da República Federativa do Brasil, 2012)

Temos um problema de antinomia, que deve ser resolvido através da aplicação de regras hermenêuticas e princípios jurídicos.

Por ser norma especial, a boa hermenêutica indica que não se poderia aplicar o artigo 84 , VI para a organização e o funcionamento 
da polícia. Contudo, essa solução simplista, não atende ao princípio da unidade da constituição e da razoabilidade, sendo cogente a busca pela harmonia dessas normas constitucionais.

Incialmente, temos o seguinte dilema: as regras de organização e funcionamento da polícia judiciária estão abrangidas pelo princípio da reserva legal, ou podem ser objeto de norma infralegal? Para responder esse questionamento podemos primeiro, analisar a aplicabilidade da norma constitucional e, ao mesmo tempo, buscar o sentido da norma.

Segundo José Afonso da Silva (2002), existem as normas constitucionais de eficácia plena, as normas de eficácia contida, as normas de eficácia limitada, e as normas programáticas. As primeiras produzem todos os efeitos jurídicos, independentemente de outras normas. As segundas são normas que, embora produzam efeitos jurídicos, podem ser restringidas por regulamentação infraconstitucional. As terceiras são normas que dependem de regulamentação para terem plena eficácia. As últimas são normas que estabelecem regras gerais a serem seguidas pelo Estado.

Além disso, uma das regras hermenêuticas mais disseminadas pela doutrina é a que afirma não existir frase ou palavra inútil, supérflua ou sem efeito, no texto legal. Por outro lado, a hermenêutica desaconselha a interpretação literal do texto, devendo ser buscado seu espírito ou sua intenção, procurando a plena eficácia da regra jurídica.

Com isso, temos, pelo menos, duas formas de tratar o $\$ 7^{\circ}$ do artigo 144: como norma programática, ou de eficácia limitada, direcionada somente ao Estado Legislador, para que este edite lei sobre organização e o funcionamento dos órgãos de segurança, a qual deve garantir a eficiência da atividade policial; ou como norma de eficácia plena direcionada a todo o Poder Público, ou seja, ao Poder Legislativo (quando for legislar sobre o assunto), ao Poder Executivo (tanto no exercício da atividade regulamentar, quanto na prática de atos que tiverem repercussão na organização e funcionamento da polícia) e ao Poder Judiciário (quando for interpretar e aplicar tais normas).

Na primeira interpretação, somente uma lei, complementar, ordinária ou delegada, poderia organizar e regular o funcionamento da polícia. Ou seja, aquilo que não estivesse de acordo com uma lei, não poderia ser realizado. 
Essa visão pode ser defendida tendo como fundamento o princípio constitucional implícito da segurança jurídica, pois evitaria atos, normas e interpretações subjetivas e abusivas.

Contudo, não parece razoável, sendo até mesmo uma contradição, que se restrinja a regulação da organização e da atuação da polícia somente aos preceitos que estejam estabelecidos em lei, já que isso pode inviabilizar a própria norma constitucional que impõe que se regule a polícia de forma a tornar suas atividades eficientes.

Pela segunda interpretação, qualquer ato normativo, expedido por órgão competente, poderia organizar e regular o funcionamento da polícia, independentemente da existência de lei em sentido estrito tratando sobre o caso.

Na primeira interpretação, há evidente exclusão da aplicação do inciso VI do artigo 84. Já na segunda, haveria uma harmonia do tal norma.

Do exposto, com base nos princípios da unidade da constituição e da razoabilidade, somado aos princípios da juridicidade e da supremacia do interesse público, podemos concluir que, embora haja evidente preferência do constituinte pela existência de lei em sentido estrito que regule a organização e o funcionamento da Polícia Judiciária de forma a garantir a eficiência de suas atividades, é possível a regulamentação de suas atividades por norma infralegal, direcionada a eficiência de suas atividades, desde que não desrespeite o ordenamento jurídico.

Assim, diante do preceito constitucional específico que preza pela eficiência da atividade policial, e havendo a omissão do legislador infraconstitucional, não se pode limitar o poder-dever dos órgãos policiais, já que a constituição não fez tal ressalva, aplicando-se à atividade de polícia judiciária a teoria dos poderes implícitos.

O Supremo Tribunal Federal reconhece a aplicação da teoria dos poderes implícitos na atividade de polícia judiciária, conforme acordão a seguir:

HABEAS CORPUS. CONSTITUCIONAL E PROCESSUAL PENAL. CONDUÇÃO DO INVESTIGADO À AUTORIDADE POLICIAL PARA ESCLARECIMENTOS. POSSIBILIDADE. INTELIGENCIA DO ART. 144, \& 4\%, 
DA CONSTITUIÇÃO FEDERAL E DO ART. $6^{\circ}$ DO CPP. DESNECESSIDADE DE MANDADO DE PRISATO OU DE ESTADO DE FLAGRÂNCIA. DESNECESSIDADE DE INVOCAÇAOO DA TEORIA OU DOUTRINA DOS PODERES IMPLÍCITOS. PRISÃO CAUTELAR DECRETADA POR DECISÃO JUDICIAL, APÓS A CONFISSÃO INFORMAL E O INTERROGATÓRIO DO INDICIADO. LEGITIMIDADE. OBSERVÂNCIA DA CLÁUSULA CONSTITUCIONAL DA RESERVA DE JURISDIÇÃO. USO DE ALGEMAS DEVIDAMENTE JUSTIFICADO. CONDENAÇÃO BASEADA EM PROVAS IDONNEAS E SUFICIENTES. NULIDADE PROCESSUAIS NÄO VERIFICADAS. LEGITIMIDADE DOS FUNDAMENTOS DA PRISATO PREVENTIVA. GARANTIA DA ORDEM PÚBLICA E CONVENIÊNCIA DA INSTRUÇÃO CRIMINAL. ORDEM DENEGADA. I - A própria Constituição Federal assegura, em seu art. 144, S $4^{\circ}$, às policias civis, dirigidas por delegados de polícia de carreira, as funçôes de policia judiciária e a apuração de infraçóes penais. II - $O$ art. $6^{\circ}$ do Código de Processo Penal, por sua vez, estabelece as providências que devem ser tomadas pela autoridade policial quando tiver conbecimento da ocorrência de um delito, todas dispostas nos incisos II a VI. III - Legitimidade dos agentes policiais, sob o comando da autoridade policial competente (art. $4^{\circ}$ do CPP), para tomar todas as providências necessárias à elucidação de um delito, incluindo-se aí a condução de pessoas para prestar esclarecimentos, resguardadas as garantias legais e constitucionais dos conduzidos. $I V$ - Desnecessidade de invocação da chamada teoria ou doutrina dos poderes implícitos, construída pela Suprema Corte norte-americana e incorporada ao nosso ordenamento jurídico, uma vez que há previsão expressa, na Constituição e no Código de Processo Penal, que dá poderes à polícia civil para investigar a prática de eventuais infrações penais, bem como para exercer as funções de polícia judiciária. (BRASIL, Supremo Tribunal Federal, HC: 107644 SP, Relator: Min. Ricardo Lewandowski, 2011) (grifo nosso).

Assim, diante de situações não previstas expressamente pela lei, mas que, sob pena de prejuízos à eficiência da persecução penal, demonstrem a necessidade de pronta atuação da Polícia Judiciária, aplica-se a teoria dos poderes implícitos. 


\section{Consideraçốes Finais}

Por envolver a restrição ou grave ameaça a um dos principais direitos individuais que é a liberdade, a atividade de polícia judiciária sempre sofreu grande limitação por parte da doutrina, que não aceitava a prática de atos que não fossem expressamente previstos em lei.

A superação do antigo paradigma da legalidade com a adoção da idéia de juridicidade, somada a constitucionalização do princípio da eficiência, vem criando um ambiente favorável para a aceitação da Teoria dos Poderes Implícitos em vários ramos da atividade estatal, onde se inclui a Polícia Judiciária.

Assim, a atividade de polícia judiciária, por imperativo constitucional, tem o dever de ser eficiente, podendo socorrer-se tanto de normas legais e infralegais, como da Teoria dos Poderes Implícitos, desde que observado os limites do sistema jurídico, com é o caso das garantias legais e constitucionais dos envolvidos.

Com isso, antigos dogmas, como é o caso da proibição da condução de suspeito para averiguação sem que tenha sido caracterizada a situação flagrancial e a ausência de fundamento legal para requisição de pessoa do povo para acompanhar buscas domiciliares sob pena de configuração do crime de desobediência, passam a ser questionados diante do dever e responsabilidade constitucional do serviço de segurança pública de forma eficiente. Nessa mesma linha, não sendo considerado o lugar um domicílio, poderá ser expedido mandado de busca pelo delegado de polícia, independentemente de autorização judicial.

João Conrado Ponte de Almeida

O autor é Delegado de Polícia Federal lotado na SuperinTENDÊNCIA Regional do CEARÁ, tendo atuado Na APURAÇão de CRIMES AMBIENTAIS, PATRIMONIAIS, FINANCEIROS, ALÉM DE CRIMES contra a Administração Pública. É Bacharel em Direito pela Universidade Federal do Ceará e pós-graduado em Direito Empresarial pela Universidade Estadual do Ceará. 


\section{ABSTRACT}

\section{Applicability of the Theory of Implied Powers in Judicial Police Activity}

The present work is an analysis of the possibility of application in the activity of the judicial police, the Theory of Implied Powers, who came up through the decision of the U.S. Supreme Court in McCulloch v. Maryland, where it was decided that there must be a reasonable relationship functions between the bodies established by the Constitution and the means used by them to fulfill their mister and the means adopted must not be prohibited by the constitution. This theory is opposed to the principles of legality and efficiency provided for in Article 37 of the Constitution of the Federative Republic of Brazil in 1988, in order to apply it so as not to injure the principles of reasonableness, legal certainty and due criminal process.

KEYwORDS: Theory of Implied Powers. Judicial Police. Principles of legality and efficiency.

\section{REREFÊNCIAS}

BAYLEY, David H. Padroes de policiamento: uma análise comparativa internacional. Tradução de Renê Alexandre Belmonte. São Paulo: EDUSP, 2001.

BRASIL. Constituição da República Federativa do Brasil: promulgada em 5 de outubro de 1988. In: Vade Mecum. São Paulo: Saraiva, 2012.

BRASIL. Lei no 5.172, de 25 de outubro de 1966. In: Vade Mecum. São Paulo: Saraiva, 2012.

BRASIL. Decreto-Lei n ${ }^{\circ}$ 4.657, de 4 de setembro de 1942. In: Vade Mecum. São Paulo: Saraiva, 2012.

BRASIL. Exposição de Motivos do Código de Processo Penal, de 8 de setembro de 1941. In: Vade Mecum. São Paulo: Saraiva, 2012.

BRASIL. Supremo Tribunal Federal. Segunda Turma. Recurso Extraordinário n 539130. Recorrente: Estado do Rio Grande do Sul. Recorrido: Brasif S/A Administração e Participações. Relator: Ministra Ellen Gracie. Brasília, DF, 04 de dezembro de 2009. Disponível em: <http://www.stf.jus.br/portal/jurisprudencia/ listarJurisprudencia.asp?s $1=\% 28539130 \% 29 \&$ base $=$ baseAcordaos \&url=http://tinyurl.com/cz43cf3 >. Acesso em: 13 mar. 2014 
BRASIL. Supremo Tribunal Federal. Primeira Turma. Recurso Ordinário em Habeas Corpus n 95782. Recorrente: Raimundo de Paula dos Santos. Recorrido: Ministério Público Federal. Relator: Ministro Luiz Fux. Brasília, DF, 04 de agosto de 2011. Disponível em: <http://www.stf.jus.br/portal/jurisprudencia/listarJurisprudencia. asp?s1=\%2895782\%29\&base=baseAcordaos\&url=http://tinyurl. com/b7k488p>. Acesso em 13 mar. 2014

BRASIL. Tribunal Regional Federal (1. Região). $2^{\mathrm{a}}$ Turma Suplementar. Apelação Civel n 200434000122295. Relator: Juiz Federal Marcelo Dolzany da Costa. Brasília, DF, 02 de julho de 2013. Disponível em: <http://jurisprudencia.trf1.jus.br/busca/>. Acesso em: 15 mar. 2014

BRASIL. Supremo Tribunal Federal. Segunda Turma. Habeas Corpus $n$ 89837. Paciente: Emanuel Loureiro Ferreira. Coator: Presidente do Superior Tribunal de Justiça. Relator: Ministro Celso de Melo. Brasília, DF, 20 de outubro de 2009. Disponível em: <http://www. stf.jus.br/portal/jurisprudencia/visualizarEmenta.asp?s1=00016366 2\&base $=$ baseAcordaos $>$. Acesso em: 13 mar. 2014

BRASIL. Superior Tribunal de Justiça. Segunda Turma. Agravo Regimental no Recurso Especial n 1119799. Relator: Ministro Humberto Martins. Disponível em: <http://www.stj.jus.br/SCON/ jurisprudencia/toc.jsp?tipo_visualizacao $=$ null\&livre $=\% 281119799$ $\% 29+\mathrm{E}+\% 28 \% 22 \mathrm{HUMBERTO}+\mathrm{MARTINS} \% 22 \% 29 . \mathrm{min} . \& \mathrm{~b}=\mathrm{A}$ COR\&thesaurus=JURIDICO $>$. Acesso em 20 de mar. 2014.

BRASIL. Supremo Tribunal Federal. Primeira Turma. Habeas Corpus $\mathrm{n}$ 107644. Paciente: Alessandro Rodrigues. Coator: Superior Tribunal de Justiça. Relator: Ministro Ricardo Lewandowski. Brasília, DF, 06 de setembro de 2011. Disponível em: <http://www.stf.jus.br/ portal/jurisprudencia/visualizarEmenta.asp?s $1=000180872 \&$ base $=$ baseAcordaos >. Acesso em: 10 mar. 2014

DI PIETRO, Maria Sylvia Zanella. Direito Administrativo. 13 ed. São Paulo: Atlas. 2002.

ESTORNINHO, Maria João. A fuga para o direito privado. Coimbra: Almedina, 1999.

FERRAJOLI, Luigi. Direito e razão: teoria do garantismo penal. Tradução Ana Paula Zomer, Fauzi Hassan Choukr, Juarez Tavares e Luiz Flávio Gomes. São Paulo: Editora Revista dos Tribunais, 2002. 
FRANÇA, Vladimir da Rocha. Eficiência administrativa. In: Revista de Direito Administrativo. Rio de Janeiro: Renovar, n. 220, abr./jul. 2000, p. 168.

FRANÇA, Vladimir da Rocha. Eficiência administrativa na Constituição Federal. Jus Navigandi, Teresina, ano 6, n. 49, 1 fev. 2001. Disponível em: http://jus.com.br/artigos/344>. Acesso em: 6 fev. 2014.

GASPARINI, Diogenes. Direito Administrativo. 11. Ed. São Paulo: Saraiva, 2006.

MEIRELLES, Hely Lopes. Direito Administrativo brasileiro. 22 ed. São Paulo: Malheiros, 1997.

MEIRELLES, Helly Lopes. Direito administrativo brasileiro. $32^{a}$ ed. São Paulo: Malheiros, 2006.

MELLO, Celso Antônio Bandeira de. Lei e regulamento - a chamada "reserva de lei" - as delegaçóes legislativas disfarçadas. Revista Trimestral de Direito Público. São Paulo, n. 49/50, p. 5-16, 2005.

MELLO, Celso Antônio Bandeira de. Curso de Direito Administrativo. São Paulo: Malheiros, 2009.

MONET, Jean-Claude. Polícias e Sociedades na Europa. Tradução de Mary Amazonas Leite de Barros. São Paulo: Editora Universidade de São Paulo, 2001.

MORAES, Alexandre de. Reforma Administrativa: Emenda Constitucional no 19/98. São Paulo: Atlas, 1999.

SILVA, José Afonso da. Aplicabilidade das Normas Constitucionais, $6^{a}$ edição, São Paulo: Malheiros, 2002.

SILVA, José Afonso da. Curso de direito constitucional positivo.18 ed. rev. e atual. São Paulo: Malheiros. 2000.

ZACCARIOTTO, José Pedro. A Polícia Judiciária no Estado Democrático de Direito. São Paulo: Brazilian Books, 2005.

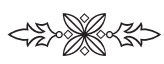

